\title{
Environmental factors affecting the quality and quantity of hemoglobin in Chironomus larvae (Diptera: Chironomidae)
}

\author{
Koichiro Kawai ${ }^{1)}$, Michita Hashimoto ${ }^{2)}$ and Hiromichi Imabayashi ${ }^{1)}$ \\ 1) Laboratory of Ecology, Faculty of Applied Biological Science, Hiroshima University, \\ Kagamiyama 1-4-4, Higashihiroshima, 739-8528 Japan \\ 2) Mizushima-cho 2962, Yatsushiro, Kumamoto, 531-0076 Japan
}

(Received: 6 February 2004; Accepted: 20 July 2004)

\begin{abstract}
The total $\mathrm{Hb}$ content and the electrophoretically distinguishable components were compared among 10 species of Chironomus. The respiration rates and the survival rates under anoxia were also evaluated for all species. Although larvae used for experiments were all reared under the same laboratory condition, the $\mathrm{Hb}$ content and composition differed interspecifically, suggesting genetic control of $\mathrm{Hb}$ production in Chironomus. However, the phylogenetic relationship inferred from a cluster analysis of $\mathrm{Hb}$ components differed greatly from the phylogeny based on randomly amplified polymorphic DNA (RAPD) analysis. The phylogenetic congruence suggests that some convergent evolution occurs in $\mathrm{Hb}$ composition of some lentic Chironomus species. Among the three factors, respiration rate, total $\mathrm{Hb}$ content and $\mathrm{Hb}$ diversity, the survival duration under anoxia was significantly correlated with the $\mathrm{Hb}$ content and respiration rate. In the species inhabiting a lentic environment where the chironomids are frequently exposed to low oxygen conditions, high respiration rates and high survival rates may be achieved by possession of abundant and specific Hbs compared with the lotic species' $\mathrm{Hb}$.
\end{abstract}

Key words: anoxic survival, Chironomus, hemoglobin, respiration rate

\section{INTRODUCTION}

Chironomid larvae of the genus Chironomus are known to live in a wide variety of waters; e.g., eutrophic lake, polluted river, brackish water, hot springs and acidic water (Sasa and Kikuchi, 1995). Interspecific differences in habitats are owing to their preference for and/or tolerance to various environmental conditions. Larvae of most species of this genus possess a large amount of hemoglobin $(\mathrm{Hb})$ in the body fluid, comprising many components which differ interspecifically (Baur et al., 1983; Kawai and Sakamoto, 1992).

To clarify how environmental factors contribute to various respirational properties, the total $\mathrm{Hb}$ content and the elec- trophoretically distinguishable $\mathrm{Hb}$ components as well as survival rates under anoxia and respiration rates were compared among 10 species of Chironomus. The determinant factors for $\mathrm{Hb}$ composition and concentration were discussed.

\section{Materials And Methods}

\section{Chironomids and rearing method}

Mature larvae of all species except for Chironomus plumosus (Linnaeus, 1758) were obtained by laboratory cultures. Adult midges of C. fusciceps Yamamoto, 1990 were stenogamic, and fertilized egg masses were easily obtained in a small space ( $5 \mathrm{~cm}$ in height). As for $C$. kiiensis Tokunaga, 1936, C. okinawanus Hasewaga et Sasa, 1987 and C. javanus (Kieffer, 
$1924)$, a medium space $(30 \mathrm{~cm}$ at the highest) was required for fertilization. For the remaining 5 species, C. circumdatus (Kieffer, 1916), C. flaviplumus (Tokunaga, 1940), C. nippodorsalis (Sasa, 1979), C. nipponensis Tokunaga, 1940 and C. yoshimatsui Martin et Sublette, 1972, fertilized egg masses were obtained in a large space (higher than $30 \mathrm{~cm}$ ). Fertilized egg masses of $C$. plumosus could not be obtained in the laboratory, and thus mature larvae were obtained by rearing the hatchings of the egg masses laid by females captured in the field. Species identification of C. plumosus was based on the emerged male adults according to the taxonomic key by Sasa and Kikuchi (1995).

For rearing experiments, a milk-containing agar medium, originally described in Shirota (1969), was used as follows. Newly hatched larvae were reared at a density of 100 individuals per plastic container $(\phi 15 \times \mathrm{H} 9 \mathrm{~cm})$ at the room temperature. Each container was layered with 200 $\mathrm{ml}$ of $1 \%(\mathrm{w} / \mathrm{v})$ agar containing $2 \%(\mathrm{v} / \mathrm{v})$ milk (fat content $3.5 \%$ ) at the bottom, filled with $600 \mathrm{ml}$ of dechlorinated water and aerated through an airstone. As the material for tube (or case) building, $50 \mathrm{ml}$ of glass beads $(0.1 \mathrm{~mm}$ in diameter) was spread on the agar plate.

\section{Hb analyses}

Larvae are usually very small and difficult to weigh individually, thus individual quantification of $\mathrm{Hb}$ was practically impossible. Therefore, an adequate number of larvae was used as a sample and measured for wet weight, and total $\mathrm{Hb}$ was prepared by homogenization of larvae in a small amount of distilled water, followed by centrifugation of the homogenate at $13,000 \mathrm{rpm}$ for $10 \mathrm{~min}$ at $4^{\circ} \mathrm{C}$ and lyophilization of the supernatant.

Total $\mathrm{Hb}$ content ( $\mu \mathrm{g} /$ ind.) was measured by the cyanmethemoglobin method (van Assendelft and Zijlstra, 1975) using Nescort hemokit-N (Nihon Shoji Co., Ltd., Osaka, Japan) as a standard solution.

$\mathrm{Hb}$ components were separated by poly- acrylamide gel electrophoresis (PAGE), on the basis of Laemmli (1970), with some modifications. The total $\mathrm{Hb}$ was mixed with a sample buffer, $\mathrm{pH}$ 6.8, without 2mercaptoethanol, and electrophoresed at $30 \mathrm{~mA}$ for $2 \mathrm{hrs}$. The gel plate was composed of a stacking gel (4\% acrylamide in $0.125 \mathrm{M}$ Tris- $\mathrm{Cl}, \mathrm{pH}$ 6.8) and a separation gel $(15 \%$ acrylamide in $0.375 \mathrm{M}$ Tris- $\mathrm{Cl}$, $\mathrm{pH}$ 8.8). After running, the gel was stained with a DAB buffer (Merck, Darmstadt, Germany) using benzidin reaction.

\section{Template DNA preparation and RAPD anal- ysis}

Template DNA for PCR was preparated using Easy-DNA ${ }^{\mathrm{TM}}$ Kit (Invitrogen, San Diego, CA, USA), according to the manufacturer's instruction. Randomly amplified polymorphic DNA (RAPD) analysis was performed using a kit (Ready-ToGo RAPD Analysis Beads, Amersham Biosciences, Piscataway, NJ, USA) with a thermal cycler (THERMO PROCESSOR TR100, Taitec, Koshigaya, Saitama, Japan). One (Primer 04) of a set of oligonucleotides (RAPD Analysis Primer Set, Amersham Biosciences, Piscataway, NJ, USA) was used as a PCR primer. The sequence was 5'-AAGAGCCCGT-3'.

\section{Calculation of dissimilarity (D) value}

D value (Gilbert et al., 1990) was calculated by $\mathrm{D}=\mathrm{Nab} /(\mathrm{Na}+\mathrm{Nb})$, where $\mathrm{Nab}$ was the number of fragments which were not shared by individuals $\mathrm{a}$ and $\mathrm{b}$, and $\mathrm{Na}$ and $\mathrm{Nb}$ were the number of fragments for individuals a and $\mathrm{b}$, respectively. A dendrogram was constructed by the UPG (Unweighted Pair-Group Clustering) method (Nei, 1975).

\section{Survival duration in an anoxic condition and respiration rates}

Survival in an anoxic condition was examined by the method described by Hirabayashi and Hayashi (1994). In brief, five to 15 individuals of the 4 th instar larvae of each species were put into the BOD bottle (Sibata Scientific Technology Ltd., Tokyo, 
Japan) in which dissolved oxygen had been almost completely driven out $(<0.5$ $\mathrm{mgO}_{2} / 1$ ) by bubbling of nitrogen air. Survival was observed at 6-hour intervals until all the individuals died. Death was judged as a lack of undulational behaviour, no response to physical stimuli, and/ or changes in body shape and color. Time for $50 \%$ survival was estimated on the basis of survival curves. The experiments were performed 4-8 times for each species.

Respiration rate was measured with a BOD bottle of approximately $100 \mathrm{ml}$ in volume. Ten to 50 individuals of the 4 th instar larvae were put into the bottle at $25^{\circ} \mathrm{C}$ which was filled with water saturated with oxygen by air bubbling and spread with $10 \mathrm{ml}$ of glass beads. A bottle without larvae was also incubated at $25^{\circ} \mathrm{C}$ as a control. Three hours later, dissolved oxygen concentration in the water was measured by Winkler's method (Alsterburg, 1925). Respiration rate $\left(\mu \mathrm{gO}_{2} / \mathrm{hr} /\right.$ indiv.) was calculated from the difference in the amount of dissolved oxygen between the control bottle and the sample bottle. The experiments were performed 7-12 times for each species.

\section{RESULTS}

\section{$\mathrm{Hb}$ content and components}

$\mathrm{Hb}$ content was higher than $150 \mu \mathrm{g}$ for 3 large species, C. nippodorsalis, C. nipponensis and C. plumosus. It was low $(<40 \mu \mathrm{g})$ for C. fusciceps, C. javanus and C. yoshimatsui and was in the range of $40-70 \mu \mathrm{g}$ for other species (Table 1). Differences in $\mathrm{Hb}$ components among the species are shown in Fig. 1. A total of 25 different $\mathrm{Hb}$ bands was detected by PAGE analysis and they were numbered in the order of the distance from the electrophoretic origin. Some bands were common to different species. The band 25 was common to all species except for $C$. fusciceps and C. okinawanus. The bands 1 and 13 were common to C. fusciceps, C. kiiensis, C. flaviplumus, C. yoshimatsui, C. circumdatus and C. nipponensis; and C. fusciceps, C. flaviplumus, C. javanus, C. okinawanus, C. nippodorsalis and $C$. nipponensis, respectively. The bands 7 and 11 were common to $C$. fusciceps, C. flaviplumus, C. javanus, C. circumdatus and C. plumosus; and C. flaviplumus, C. okinawanus, C. nippodorsalis, C. nipponensis and C. plumosus, respectively. On the other hand, some bands were species-specific. The bands $4 ; 14$ and 20; 18; 21; 22; 23 ; and 24 were specific to C. fusciceps;

Table 1. Body wet-weight, 50\% survival duration in anoxic condition, respiration rate, $\mathrm{Hb}$ content and $\mathrm{Hb}$ composition of 10 Chironomus species.

\begin{tabular}{lccccc}
\hline \hline \multicolumn{1}{c}{ Species } & $\begin{array}{c}\text { Body } \\
\text { wet-weight } \\
(\mathrm{mg})\end{array}$ & $\begin{array}{c}\text { Survival } \\
\text { duration } \\
(\mathrm{hr})\end{array}$ & $\begin{array}{c}\text { Respiration } \\
\text { rate } \\
\left(\mu \mathrm{gO}_{2} / \mathrm{hr}\right)\end{array}$ & $\begin{array}{c}\mathrm{Hb} \\
\text { content } \\
(\mu \mathrm{g})\end{array}$ & $\begin{array}{c}\mathrm{Hb} \\
\text { composition } \\
(\text { no. of bands) }\end{array}$ \\
\hline C. fusciceps & 1.96 & $10.0 \pm 1.15^{\mathrm{a}}(7)$ & $1.08 \pm 0.25^{\mathrm{a}}(9)$ & 37.5 & 5 \\
C. kiiensis & 2.23 & $27.3 \pm 3.13^{\mathrm{c}}(6)$ & $1.78 \pm 0.38^{\mathrm{cd}}(9)$ & 61.9 & 7 \\
C. flaviplumus & 2.68 & $23.8 \pm 3.19^{\mathrm{b}}(6)$ & $1.85 \pm 0.31^{\mathrm{cd}}(9)$ & 69.6 & 8 \\
C. javanus & 2.81 & $9.93 \pm 2.30^{\mathrm{a}}(8)$ & $1.43 \pm 0.17^{\mathrm{b}}(8)$ & 39.0 & 6 \\
C. yoshimatsui & 2.86 & $22.7 \pm 1.54^{\mathrm{b}}(6)$ & $1.92 \pm 0.59^{\mathrm{cde}}(8)$ & 37.5 & 11 \\
C. okinawanus & 2.95 & $11.2 \pm 0.00^{\mathrm{a}}(5)$ & $1.56 \pm 0.40^{\mathrm{bc}}(9)$ & 44.4 & 4 \\
C. circumdatus & 3.53 & $27.0 \pm 1.60^{\mathrm{c}}(5)$ & $1.55 \pm 0.54^{\mathrm{bc}}(12)$ & 56.5 & 6 \\
C. nippodorsalis & 4.06 & $34.4 \pm 4.79^{\mathrm{d}}(6)$ & $2.23 \pm 0.55^{\mathrm{de}}(9)$ & 185 & 6 \\
C. nipponensis & 4.29 & $27.3 \pm 6.38^{\mathrm{bc}}(7)$ & $2.45 \pm 0.58^{\mathrm{e}}(7)$ & 151 & 8 \\
C. plumosus & 11.3 & $24.7 \pm 1.06^{\mathrm{b}}(4)$ & $3.40 \pm 0.49^{\mathrm{f}}(8)$ & 222 & 7 \\
\hline
\end{tabular}

Mean \pm standard deviation and the number of experiments (in parentheses) were shown for survival duration and respiration rate. Values within columns followed by different superscript letters a-f are significantly different $(P<0.05)$ by Student's $t$-test. 


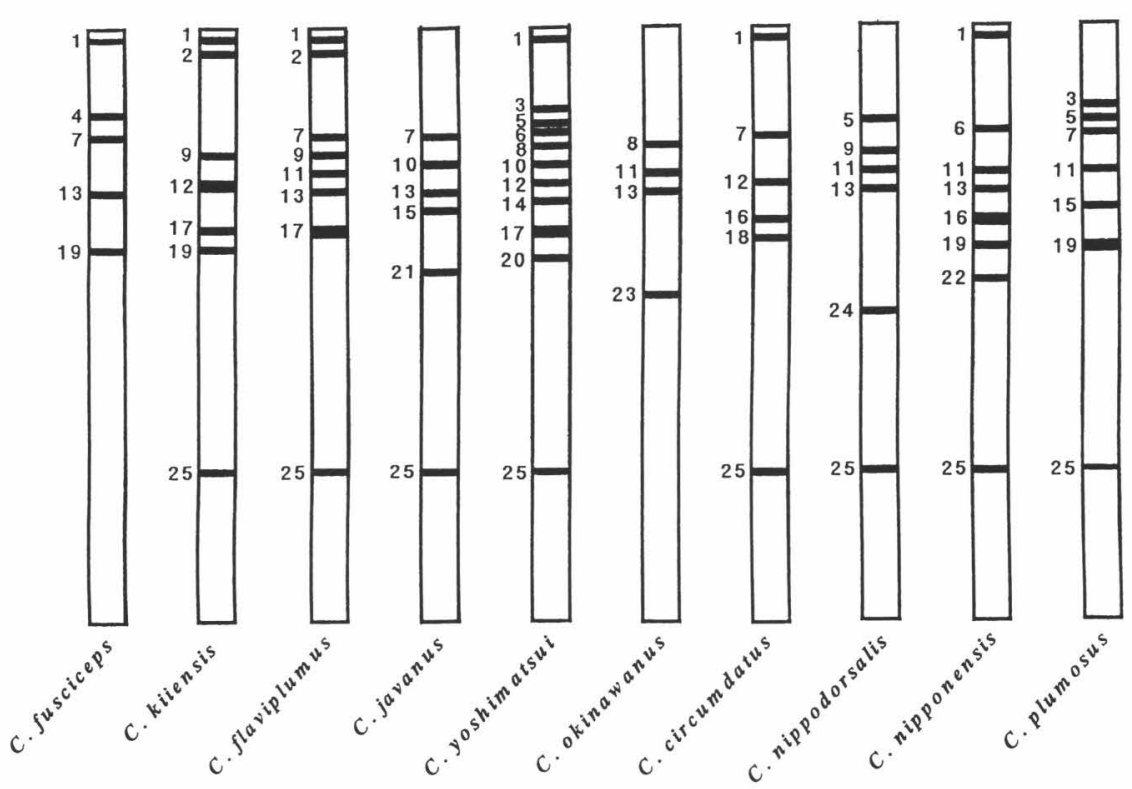

Fig. 1. Hb components for 10 species analysed by PAGE. Each $\mathrm{Hb}$ band was numbered in the order of the distance from the electrophoretic origin.

(A)
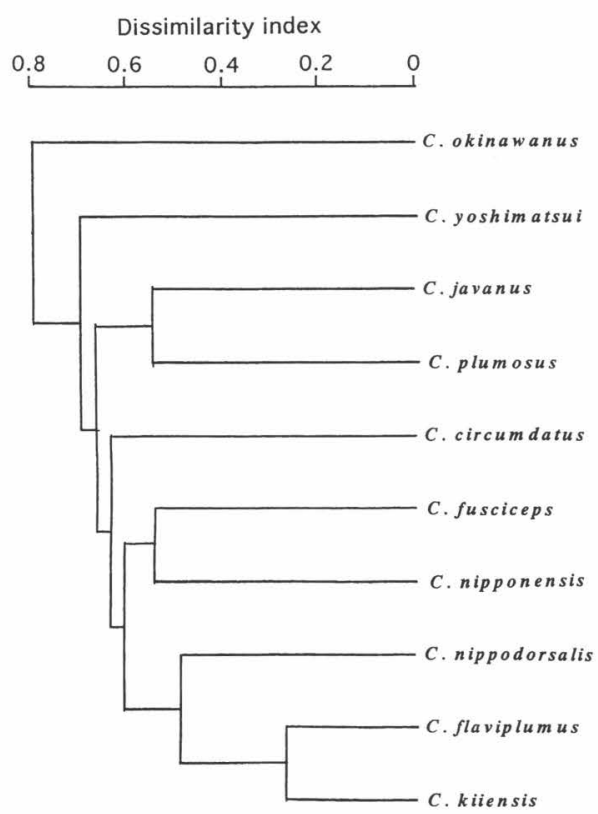

(B)
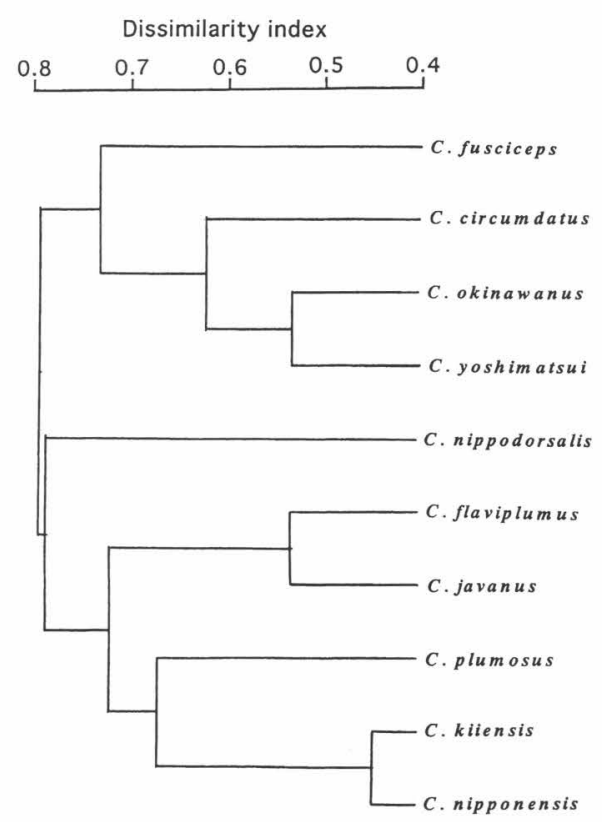

Fig. 2. A, A clustering pattern of 10 species on the basis of $\mathrm{Hb}$ components; B, A clustering pattern of 10 species on the basis of DNA fragments amplified in RAPD-PCR.

C. yoshimatsui; C. circumdatus; C. javanus; C. nipponensis; C. okinawanus; and C. nippodorsalis, respectively.

\section{Phylogeny on $\mathrm{Hb}$ components and DNA}

Clustering on the basis of $\mathrm{Hb}$ composition is shown in Fig. 2A. A large cluster was made by all species except for C. oki- 

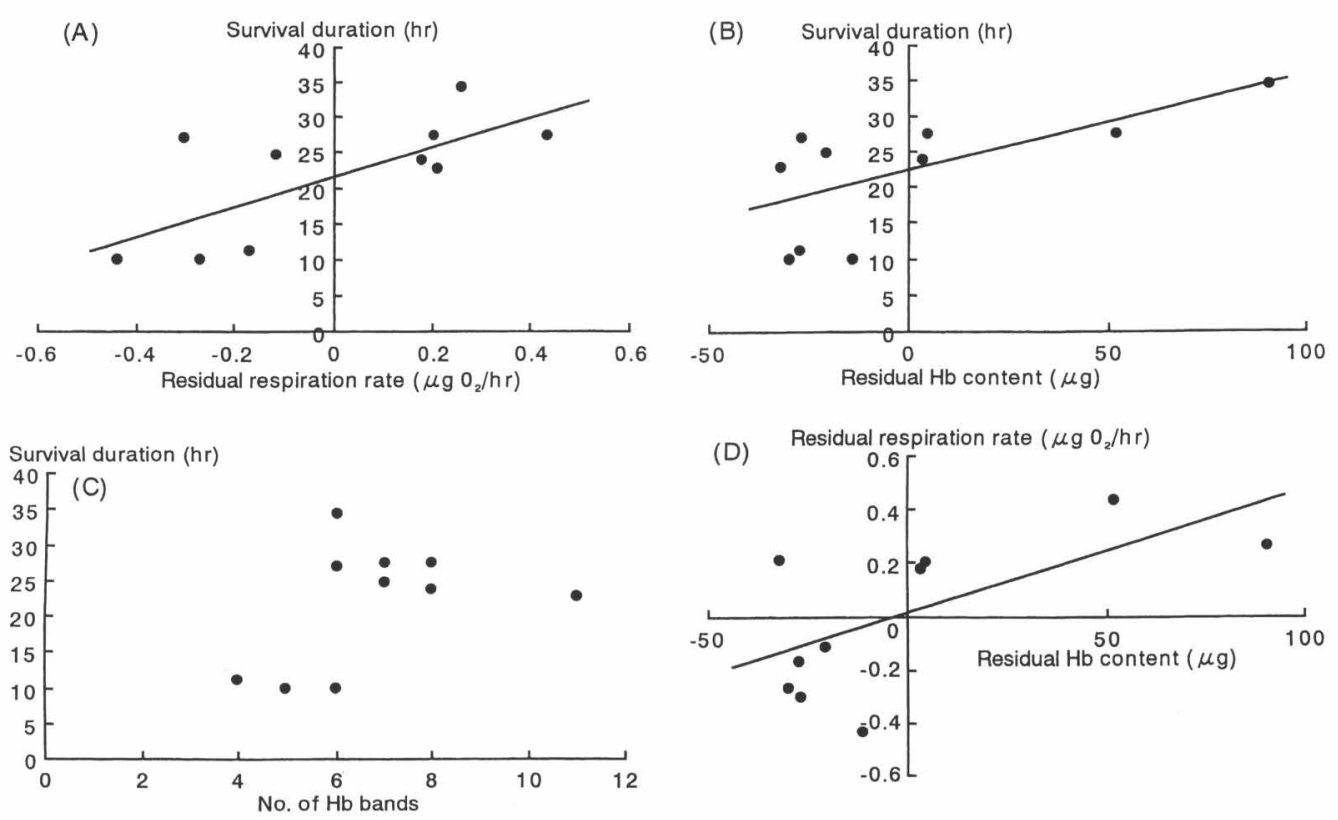

Fig. 3. Relationships among some respirational parameters. A, Relationship between the residual respiration rate and survival duration $(r=0.70, P<0.05)$; B, Relationship between the residual $\mathrm{Hb}$ content and survival duration $(r=0.65, P<0.05)$; C, Relationship between Hb composition and survival duration $(r=0.41, P>0.05)$; D, Relationship between the residual $\mathrm{Hb}$ content and the residual respiration rate $(r=0.66, P<0.05)$.

nawanus and C. yoshimatsui, which were both distant from the other 8 species. $C$. javanus and C. plumosus; and C. fusciceps and $C$. nipponensis, each made a small cluster. C. nippodorsalis, C. flaviplumus and $C$. kiiensis made another small cluster, among which the latter two species made a relatively intimate cluster.

Clustering on the basis of the DNA fragments amplified in RAPD-PCR is shown in Fig. 2B. Largely three clusters were made; C. fusciceps, C. circumdatus, C. okinawanus and C. yoshimatsui; C. nippodorsalis; C. flaviplumus, C. javanus, C. plumosus, C. kiiensis and $C$. nipponensis. C. okinawanus and $C$. yoshimatsui; C. flaviplumus and C. javanus; and $C$. kiiensis and $C$. nipponensis, each constructed a small cluster.

Anoxic tolerance and the factors affecting it

The body wet-weight was by far the highest for the largest species, C. plumosus and was in the range of $2.0-4.3 \mathrm{mg}$ for all other species (Table 1). The mean 50\% survival duration of C. nippodorsalis in anoxic conditions was significantly the longest $(34.4 \mathrm{hr})$ among the species $(P<$ $0.05, t$-test). Those of C. fusciceps, C. javanus and $C$. okinawanus were significantly shorter $(9.93-11.2 \mathrm{hr})$ than that of the other species $(P<0.05, t$-test $)$. It was in the range of $22.7-27.3 \mathrm{hr}$ for all other species. The mean respiration rate of $C$. plumosus was significantly the highest among the species $(P<0.05, t$-test). That of $C$. fusciceps was significantly the lowest among the species $(P<0.05, t$-test). It was in the range of $1.43-2.45 \mu \mathrm{gO}_{2}$ for all other species.

There were significant positive relationships between body wet-weight and respiration rate $(r=0.89, P<0.01)$ and between body wet-weight and $\mathrm{Hb}$ content $(r=0.81$, $P<0.01$ ) (Table 1). However, there were no significant relationships beween body wet-weight and mean survival duration $(r=0.27, P>0.05)$ and between body wetweight and $\mathrm{Hb}$ composition $(r=0.06, P>$ 0.05) (Table 1). Besides, there were no significant relationships beween $\mathrm{Hb}$ com- 
position and mean survival duration $(r=$ $0.41, P>0.05)$ (Fig. 3C). Therefore, the factors affecting the survival duration under anoxia were analyzed using the residuals for respiration rates and $\mathrm{Hb}$ contents. As a result, the survival duration was longer with increasing respiration rates $(r=0.70$, $P<0.05$ ) (Fig. 3A) and $\mathrm{Hb}$ contents $(r=$ $0.65, P<0.05)$ (Fig. 3B). The respiration rates were also correlated with the $\mathrm{Hb}$ contents $(r=0.66, P<0.05)$ (Fig. 3D).

\section{Discussion}

In this study, Hb content was high in $C$. nippodorsalis, C. nipponensis and C. plumosus, all living in lentic environments (Sasa, 1978; Yasuno et al., 1983) whereas it was low in C. fusciceps, C. yoshimatsui and $C$. okinawanus, all living in lotic waters (Hashimoto, 1977; Sasa and Hasegawa, 1983; Yamamoto, 1990). Besides, the survival duration was longer with increasing respiration rates and $\mathrm{Hb}$ contents. The respiration rates were also correlated with the $\mathrm{Hb}$ contents. These results suggest that anoxic resistance of lentic Chironomus species may be dependent on the $\mathrm{Hb}$ content.

On the other hand, C. yoshimatsui larvae are found in oxygen-poor sites in a river whereas a non-Hb bearing species, Cricotopus bicinctus (Meigen, 1818) larvae are found in more oxygen-rich sites in spite of the same oxygen concentration level at which the two species could compensate the respiration (Ohno, 1984,1985). This can be explained by the difference in body size between the two species (C. yoshimatsui is 4 times larger in body weight than C. bicinctus). Thus, a smaller species has a relatively large respiration rate per body weight which is disadvantageous to anoxia (Hayashi, 1989). In this study, however, there was no significant relationship between body wet-weight and survival duration in anoxia. Therefore, the lack of $\mathrm{Hb}$ might be partly responsible for the inability of $C$. bicinctus to live in oxygen-poor waters.

In cluster analysis on the basis of $\mathrm{Hb}$ composition, a high level of similarity was observed between $C$. flaviplumus and $C$. kiiensis, both mainly living in stagnant or lentic waters (Hashimoto, 1977). Further, C. nippodorsalis, also a lentic species, constructed a cluster with C. flaviplumus and C. kiiensis. Similarly, C. javanus, often emerging from artificial pools, made a cluster with a lentic species, C. plumosus. C. okinawanus and C. yoshimatsui were both distant from the other 8 species and different from each other. These suggest that $\mathrm{Hb}$ composition is congruent in lentic environments whereas it is admitted to diverge in lotic environment. In contrast, the clustering patterns were quite different on the basis of RAPD. Namely, the lentic 3 species, C. flaviplumus, C. kiiensis and $C$. nippodorsalis, each constructed a distinct cluster, and two other lentic species, C. javanus and C. plumosus, each participated in different clusters. Further, $C$. okinawanus and C. yoshimatsui made a cluster. Thus, it may be inferred that $\mathrm{Hb}$ composition be determined not by evolutional factor(s) but by environmental factors of habitats and that there are some evolutional congruences of $\mathrm{Hb}$ composition in the chironomid species.

Although larvae used for experiments in this study were all reared under the same laboratory condition, $\mathrm{Hb}$ content and composition differed interspecifically, suggesting some genetic control of $\mathrm{Hb}$ production in Chironomus. However, for some species of the genus Polypedilum, another common genus in the family Chironomidae, $\mathrm{Hb}$ composition has been reported to change among different rearing conditions, probably corresponding to differences in water quality, in our previous study (Kawai et al., 2000). Therefore, larval $\mathrm{Hb}$ composition of each species, reared in the laboratory, does not always reflect that of living larvae in the fields. It is desirable that rearing methods approximating natural conditions as much as possible be worked out. 


\section{REFERENCES}

Alsterburg, G. 1925. Methoden zur Bestimmung von in Wasser gelösten elementaren Sauerstoff bei Gegenwart von salpetriges Säure. Biochem. Z., 159: 36-47 (In German).

Baur, X., Dewair, M., Haegele, K., Prelicz, H., Scholl, A. and Tichy, H. 1983. Common antigenic determinants of haemoglobins as basis of immunological cross-reactivity between chironomid species (Diptera, Chironomidae): Studies with human and animal sera. Clin. Exp. Immunol., 54: 599-607.

Gilbert, D. A., Lehman, N., O’Brien, S. J. and Wayne, R. K. 1990. Genetic fingerprinting reflects population differentiation in the California Channel Island fox. Nature, 344: 746-767.

Hashimoto, H., 1977. Akamushi in Japan. Iden, 31: 76-81 (In Japanese).

Hayashi, F. 1989. Respiratory responses of aquatic insects to low oxygen concentration. Jpn. J. Limnol., 50: 255-268 (In Japanese).

Hirabayashi, K. and Hayashi, H. 1994. Horizontal distribution of benthic macroinvertebrates in Lake Kizaki, Japan. Jpn. J. Limnol., 55: 105-114.

Kawai, K., Hayashi, S. and Imabayashi, H. 2000. Differences in properties in respirational physiology among some chironomid species of the genus Polypedilum. Med. Entomol. Zool., 51: 179-185.

Kawai, K. and Sakamoto, K. 1992. Cross-reactivities of murine IgE-inducing larval hemoglobins among various chironomid species. Jpn. J. Sanit. Zool., 43: 92-103.

Laemmli, U. K., 1970. Cleavage of structural proteins during the assembly of the head of bacteriophage T4. Nature, 227: 680-685.
Nei, M. 1975. Molecular Population Genetics and Evolution. 288 pp. North Holland, Amsterdam.

Ohno, M. 1984. Ecological studies of chironomids in Tokyo II. Distribution of chironomid larvae in the Zenpukuji River. Jpn. J. Ecol., 34: 101-111 (In Japanese).

Ohno, M. 1985. Ecological studies of chironomids in Tokyo III. Anoxic resistance of 2 species of chironomid larvae distributed in the Zenpukuji River. Jpn. J. Ecol., 35: 103-111 (In Japanese).

Sasa, M., 1978. A comparative study of adults and immature stages of nine Japanese species of the genus Chironomus (Diptera, Chironomidae). Res. Rep. Natl. Inst. Environ. Stud., 3: 1-63.

Sasa, M. and Hasegawa, H. 1983. Chironomid midges of the tribe Chironomini collected from sewage ditches, eutrophicated ponds, and some clean streams in the Ryukyu Islands, southern Japan. Jpn. J. Sanit. Zool., 34: 305-341.

Sasa, M. and Kikuchi, M. 1995. Chironomidae of Japan. 333 pp. University of Tokyo Press, Tokyo.

Shirota, A. 1969. Studies on "Akamushi". 148 pp. Koseishakoseikaku, Tokyo (In Japanese).

van Assendelft, O. W. and Zijlstra, W. G. 1975. Extinction coefficients for use in equations for the spectrophotometric analysis of haemoglobin mixtures. Anal. Biochem., 69: 43-48.

Yamamoto, M. 1990. Study of the Japanese Chironomus inhabiting high acidic water (Diptera, Chironomidae) II. Jpn. J. Entomol., 58: 167-181.

Yasuno, M., Iwakuma, T., Sugaya, Y. and Sasa, M. 1983. Benthos in Japanese lakes at different trophic levels. In: Chironomids as an Indicator Organism of Environment, B182-R12-17 (ed. Yasuno, M.), pp. 21-48. Ministry of Education, Science and Culture of Japan, Tokyo (In Japanese). 